\title{
Carbon coated monolith, a mesoporous material for the removal of methyl orange from aqueous phase: adsorption and desorption studies
}

\begin{abstract}
The cordierite monolith was successfully modified to carbonaceous material termed as carbon coated monolith (CCM). Surface studies showed about $65 \%$ of the total pore volume falls in mesopore range with acidic functionality dominating over the surface. Batch adsorption experiments were carried out to study the applicability of CCM for the removal of methyl orange (MO) from aqueous solution. Different parameters such as effect of MO concentration, contact time, initial $\mathrm{pH}$, regeneration and desorption potential of CCM were studied. Optimum adsorption of MO on CCM was observed at pH $6(27.2 \mathrm{mg} / \mathrm{g})$. The increase in initial $\mathrm{MO}$ concentration from 50 to $500 \mathrm{mg} / \mathrm{L}$ leads to increase in adsorption capacity from 15.99 to $88.5 \mathrm{mg} / \mathrm{g}$. The observed equilibration time ranged in between 5000 and $5800 \mathrm{~min}$. Linear and non-linear isotherm studies showed better applicability of Freundlich model. Kinetics studies showed better fitting for pseudo-second-order model. The Weber and Morris model showed multi-linearity indicating two or more steps were involved to describe the adsorption process. Desorption studies showed maximum recovery of MO when alkaline $\mathrm{NaOH}$ solution was used as an eluent. The regeneration studies showed decrease in adsorption capacity from 47.93 to $23.76 \mathrm{mg} / \mathrm{g}$ after three cycles.
\end{abstract}

Keyword: Adsorption; Desorption; Regeneration; Methyl orange; Carbon coated monolith 